\title{
Interação Empresários-Setor Público no Turismo: uma análise institucional em Morretes, PR, Brasil
}

\author{
Bruno Martins Augusto Gomes* Nadia Giannini** \\ Carolina Poltronieri Bassani**** \\ Universidad Federal de Paraná (Brasil)
}

\begin{abstract}
Resumo: Esse artigo tem como objetivo analisar a interação entre empresários de turismo e setor público, a partir de um estudo na cidade de Morretes, localizada no sul do Brasil, utilizando a Economia Institucional. Com uma metodologia pautada na teoria fundamentada, foram realizadas seis entrevistas com empresários e representantes do setor público, além da análise documental de leis locais. A pesquisa demostrou que o contexto da interação empresários-setor público em Morretes é caracterizado pela fragilidade do órgão público de turismo e uma dependência do turismo em relação a alguns poucos empreendimentos, principalmente de gastronomia. A interação em Morretes é mais frequente na implementação das políticas públicas, sendo marcada pela persuasão, barganha e racionalidade limitada. Conclui-se que o fortalecimento de Morretes enquanto destino turístico requer a reavaliação dos hábitos pelos agentes, dentre os quais o esforço para a interação via conselho municipal de turismo.
\end{abstract}

Palavras-chave: Empresários; Setor público; Interação; Turismo; Morretes; Brasil.

Business-public sector interaction in tourism: an institutional analysis in Morretes, PR, Brazil

Abstract: This article is an analysis of the interaction between the State and private tourism enterprise as given in the city of Morretes, in South Brazil, based on Institutional Economics. With a methodology based on the grounded theory, six interviews were conducted with businessmen and representatives of the public sector, in addition to documented analysis of local laws. The research shows that the context of private-public sector interaction in Morretes is characterised by the fragility of the State tourism agenda producing an over-dependence on a few private businesses mainly relating to gastronomy. Interaction therefore between public-private sectors is more frequent than in other places but subject to a marked process of bargaining and compromises, with little or no rational basis. It is concluded that the strengthening of Morretes as a tourist destination requires significant re-adjustments among which one of the most significant is the involvement of the municipal tourism council.

Keywords: Entrepreneurs; Public sector; Interaction; Tourism; Morretes; Brazil.

\section{Introdução}

Dentre as possibilidades teóricas para fundamentar a investigação das políticas públicas de turismo como o marxismo, o elitismo, o pluralismo, neocorporativismo e a teoria sistêmica, está o institucionalismo. Mas como expõem Falaster, Zanin \& Guerrazzi (2017) apesar do institucionalismo ser uma teoria consolidada e com potencial de contribuição para o turismo, poucos pesquisadores a utilizam na área.

Dentre aqueles que a adotam estão Endres \& Matias (2018) que examinaram a trajetória dos principais atores envolvidos com o o turismo na Paraíba e em João Pessoa (Brasil), desde a década de 1970, enfocando o contexto, a trajetória e as mudanças institucionais. Béland \& Zarzeczny (2018) a partir dos casos do Canadá e dos Estados Unidos, desenvolveram uma agenda de pesquisa institucionalista para

\footnotetext{
* Universidad Federal de Paraná (Brasil); E-mail: gomesbma@gmail.com

* Universidad Federal de Paraná (Brasil); E-mail: nnagiannini@gmail.com

*** Universidad Federal de Paraná (Brasil); E-mail: carolpbassani@gmail.com
} 
explorar a relação entre o turismo médico e os sistemas nacionais de saúde. Cintra, Amâncio-Vieira \& Costa (2016) analisaram a relação entre as teorias do stakeholder e institucionalismo sociológico na perspectiva as organizações. Yew (2015), utilizando o institucionalismo, analisou como o governo de Hong Kong aborda as preocupações e controvérsias da sociedade sobre o turismo de massa. Já Meydani (2015) analisou, também por meio do institucionalismo, a decisão da Suprema Corte de Israel, sobre a política de guias de turismo. Cabral, Dias \& Gomes (2015) investigaram as ações públicas e privadas em resposta aos problemas ambientais nas praias da Ilha de Mosqueiro, litoral do Pará (Brasil), à luz da teoria institucional.

Assim, a partir da economia institucional, compreendendo instituições como hábitos coletivos de pensamento e ação, essa pesquisa tem o objetivo de analisar a interação entre empresários de turismo e setor público, por meio de um estudo na cidade de Morretes, no estado do Paraná (PR), Brasil. Pretende-se especificamente identificar o contexto que envolve a interação no município e caracterizar os hábitos que moldam o comportamento destes agentes ao interagirem.

A escolha do objeto de estudo ocorreu, pois o litoral paranaense, região turística onde Morretes está localizada, tem apresentado um crescimento do número de empresas de turismo a partir dos anos 2000 (Ipardes, 2008; Kushano Filippim e Gândara, 2013). Porém, segundo o Ipardes (2008) há evidências de pouca cooperação entre os empresários de turismo e está presente na região uma insatisfação destes agentes com o setor público. Feger et al. (2018) também identificaram no Litoral do Paraná um baixo nível de interação entre os agentes relacionados ao turismo. Frente a esse contexto se destacam os estudos de Gomes \& Pessali (2018) e de Gomes, Vargas-Sánchez \& Pessali (2014) sobre as cidades de Curitiba (capital do estado do Paraná, Brasil) e Huelva (Espanha) os quais fornecem elementos de sustentação para a problematização sobre Morretes e para a investigação das respectivas respostas.

A partir de uma pesquisa qualitativa, entrevistando empresários e agentes do setor público de Morretes, PR, Brasil, buscou-se responder as seguintes questões: como é a interação entre os empresários na cidade? Quais as instituições presentes na interação entre empresários e setor público em Morretes? Quais as lições que podem ser extraídas desta interação para as políticas públicas de turismo em destinos turísticos menores, como o caso analisado?

Para tanto a seguir, apresenta-se o referencial teórico sobre economia institucional e políticas públicas de turismo. Em seguida, expõe-se a metodologia pautada na teoria fundamentada para então discorrer sobre os resultados e as considerações finais.

\section{Hábitos na Interação entre Empresários e Setor Público no Turismo}

De acordo com Hodgson (2017) os hábitos são um conceito chave para compreender como as regras se aderem ao meio social e como as instituições se sustentam. Pessali (2015:52) acrescenta que o hábito é "uma propensão, uma inclinação, uma capacidade adquirida para agir ou pensar como em ocasiões anteriores". Assim, as instituições são um conjunto de hábitos de pensamento e ação presentes entre os membros do grupo que auxiliam estes a tomarem decisões e terem expectativas sobre o comportamento dos outros.

Pessali (2015) acrescenta que o resultado das nossas ações depende da ação de outras pessoas. Por isso, segundo este autor, a interação das pessoas precisa ser colocada na lista de fenômenos a serem investigados dadas as consequências dela para a economia, para a família ou até para a reavaliação de suas próprias decisões. Logo, em situações complexas como a interação entre pessoas, as instituições permitem uma confiança sobre como as outras responderão aos atos (Neale, 1987; Pessali, 2015). Assim, a racionalidade limitada, em oposição ao comportamento otimizador de utilidade presente na economia tradicional, é mais próxima da análise dos hábitos dos agentes, em função da evidente incapacidade destes terem conhecimento de todas as alternativas e consequências (Pessali, 2015; Simon, 1979).

Ostrom (2014) reforça que a interação humana é composta por regras (instituições) que ao serem conjugadas possibilitam ao agente a compreensão de como atuar em seu meio. Segundo a referida autora, estas regras que compõem a interação são: de fronteira (delimitam quem pode participar e como); de posição (definem o lugar de cada participante); de escolha (determinam quais ações cada cargo pode executar); de agregação (definem como os participantes podem realizar suas transações no grupo); de informação (nível de informação disponível aos participantes sobre as ações); de pagamento (benefícios e custos atribuídos das escolhas feitas pelo participante) e; de escopo (definem quais resultados são afetados pelas decisões do agente). Assim, entende-se a interação como um contato entre os agentes, no qual o comportamento de um influencia o outro, e ambos os comportamentos formam e são formados p’or um ambiente de instituições. 
Considine (2005) acrescenta que há uma interdependência entre instituições e políticas públicas na medida em que as instituições criam condições para políticas e estas também mudam ou geram instituições. As políticas públicas podem ser analisadas sob a perspectiva de um ciclo (agenda, formulação, implementação e avaliação) voltado para a resolução de um problema. Nesse ciclo a "ação e inação são institucionalmente moldadas [e] o que é anunciado como uma nova política raramente está escrita em uma folha em branco" (Considine, 2005: 2-3). Portanto, segundo este autor, as instituições não apenas restringem mas também sustentam ações de criação nas políticas públicas. Dessa maneira, elas assim afetam (e são afetadas) as atitudes e objetivos dos empresários, gestores e trabalhadores e, consequentemente, o funcionamento das empresas e setores econômicos (Sinclair \& Stabler, 2002).

Diniz (1994) afirma que o setor público e a iniciativa privada negociam buscando impedir o conflito e o seu desdobramento para fora dos grupos diretamente envolvidos. Portanto, a interação entre empresários e setor público, num contexto democrático, é predominantemente de negociação. Segundo Gomes (2018), na interação entre setor público e empresários do turismo, há uma baixa ocorrência do comando (fiscalização, punição ou recompensa) e, como exposto, uma predominância de negociação.

De acordo com Strauss (1978), a negociação é o esforço para conseguir algo por meio de um acordo entre as partes envolvidas, construído a partir de uma tensão inicial entre elas. $\mathrm{O}$ autor observa que o seu produto - os acordos - tem uma limitação temporal, podendo, decorrido um período, ser revisado, revogado ou renovado. A negociação pode se manifestar por meio da barganha, persuasão ou cooperação. A barganha é um acordo mútuo composto pela troca entre aquilo que um tem e o outro precisa, enquanto a persuasão é o acordo a partir da argumentação, não sendo necessário o defensor alterar sua condição (Anderson, 2011).

Para que os agentes interajam de forma cooperada, Axelrod (1986) observa que é importante a reflexão desses sobre os comportamentos passados, a importância que atribuem ao futuro e as recompensas possíveis advindas da cooperação. O autor acrescenta que a cooperação também é afetada pela incerteza em relação à duração da interação e a frequência com que ocorre. A incerteza pode ser reduzida aumentandp a frequência da interação, o que desestimulará comportamentos oportunistas.

Nas políticas públicas de turismo a interação entre os agentes também é fundamental, com destaque aos empresários e setor público, pois são eles que predominantemente direcionam o ciclo da política pública. Mendonça (2012) acrescenta que a eficácia no turismo depende do potencial físico, da prestação de serviços, do ambiente institucional e da interação entre os agentes. Sessa (1976) expõe que as características da política de turismo são diretamente dependentes do grau de desenvolvimento turístico do destino e também do quadro institucional do país em que esta ocorre.

Velasco (2016) defende que a análise atuação pública no turismo é abordada a partir das abordagens relacional e racional. A relacional diz respeito à política, aos atores, ideias e instituições. Já a racional está ligada à técnica, ao planejamento, à gestão pública, às metodologias e às organizações públicas e seus processos. Gomes (2018:38) acccrescenta que as polítcas públicas de turismo podem ser definidas como "um conjunto de hábitos institucionalizados no Estado vinculados às possibilidades da sua sociedade receber ou enviar turistas. Esses hábitos se manifestam no planejamento, na legislação, na oferta de serviços públicos e no fomento relacionados ao turismo".

Todavia, a atuação do setor público como coordenador do turismo em um destino requer a existência do "CPF do turismo". No Brasil, essa expressão em princípio corresponde ao Cadastro de Pessoas Físicas, mas também é utilizada nas análises de políticas públicas para se referir aos três instrumentos muito comuns no país desde a Constituição Federal de 1988: o conselho, o plano e o fundo (Alchorne, 2012; Rodrigues \& Castro, 2013). Os conselhos são desenhos instituicionais compostos por agentes do setor público e da sociedade civil, os quais trabalham em conjunto com o poder executivo na definição de diretrizes para as políticas públicas, bem como para o uso de recursos dos fundos públicos destinados à atividade. Já os fundos são uma possibilidade financeira do poder executivo na qual áreas de políticas públicas obtem uma receita própria, por exemplo, por meio de taxas, tornando estas áreas menos dependentes de repassases de verbas da admisnitração central. Os planos, por sua vez, são documentos elaborados pelo poder executivo, contendo o que deve ser realizado por ele em um dado período em relção a uma determinada área. Além desses três instrumentos, a atuação do setor público como coordenador requer um orçamento para o órgão de turismo que não se limite à folha de pagamentos dos servidores. Esses quatro aspectos, como exposto por Gomes (2018) também expressam a trajetória e a importância do turismo no setor público de um destino.

Assim, o Estado é o principal responsável pelo estímulo ao setor do turismo e, se necessário pode controlar a expansão da infrastrutura privada no destino (Velarde, 2017). Porém, a escolha de quais aspectos relacionados ao turismo estarão sujeitos à ação pública não é técnica, é uma escolha puramente 
política (Soto \& Gozález, 2005). Logo, diante da possibilidade de influência dos interesses privados exposta, reforça-se a necessidade da forte atuação do setor público no turismo, para assim agir como defensor do turismo como meio de desenvolvimento não apenas econômico mas também social.

Gomes (2018) observa que a ação coletiva dos empresários também é uma condição para o êxito da interação com o setor público, podendo ela ser observada pela capacidade dos empresários para construir uma pauta única e que contribua para desenvolvimento do destino turístico. Como expõe o autor citado, a apresentação de pautas individuais ao setor público gera para esse uma dificuldade em identificar as prioridades que devem ser atendidas. Na interação empresários-setor público deve ser observada, ainda, a defesa de ideias, especialmente dos empresários em relação ao segundo. Sob essa ótica deve ser analisado se a interação se dá na formulação de políticas públicas ou legislação, se ocorre predominante no período eleitoral e com que recorrência o setor público implementa as ideias dos empresários (Gomes, 2018).

Finalmente, a interação entre empresários e setor público nas políticas públicas de turismo pode ser sintetizada, segundo Gomes e Pessali (2018), em três hábitos resultantes: voz, saída e lealdade. De acordo com Hirschman (1973), a saída significa desistência, abandono da interação, a voz, por sua vez, representa uma ação política, a manifestação de suas ideias e a lealdade é a renuncia a sua preferência em função do compromisso com a outra parte da interação.

Os hábitos coletivos de pensamento e ação expostos fundamentam a coleta e análise dos dados bem como os resultados e conclusões expostos nas seções seguintes.

\section{Procedimentos Metodológicos}

Essa investigação foi desenvolvida de maneira qualitativa, a partir das questões de pesquisa e dos objetivos, pois buscou-se analisar os hábitos de empresários e setor público ao interagirem nas políticas públicas de turismo em Morretes, PR, Brasil. Para tanto a pesquisa se balizou na teoria fundamentada que consiste em um método relacionado à análise qualitativa que permite construir um marco conceitual integrado útil para predizer ou explicar um fenômeno (Strauss e Corbin, 2008; Bryant e Charmaz, 2010; Gomes, 2018).

Para isso foram realizadas parte das etapas da teoria fundamentada propostas por Gomes (2018): a entrevista, a transcriação e a identificação, a categorização e as codificações aberta e axial. Como o intuito nessa pesquisa não é gerar uma nova teoria, mas sim explicar um fenômeno a partir de conceitos já existentes, não foi realizada a codificação seletiva, que consiste em integrar e refinar a teoria.

$\mathrm{Na}$ coleta de dados desta pesquisa foi utilizada a entrevista, por meio de um roteiro que, seguindo as sugestões de Charmaz (2009), se voltou à identificação dos processos sociais, ações e palavras relacionados ao contexto, aspectos que participantes atribuem significado especial, suposições, além de caracterizar quem fez o que, quando, por que e como. As entrevistas foram realizadas com seis agentes, predominantemente por serem representantes das associações empresariais locais e do setor público de Morretes, PR. As entrevistas foram gravadas e obtidas por meio do deslocamento do pesquisador até a cidade, agendado previamente com os entrevistados.

Para a análise dos dados primeiramente foi criada uma legenda de identificação dos entrevistados visando manter o anonimato dos mesmos ao longo da interpretação dos dados. Em seguida, os temas do referencial teórico (representados na Figura 1 pelas partes menores do círculo interno ) foram transformados em uma legenda atribuindo um código para cada. Também foi elaborada uma legenda referente aos objetivos específicos da pesquisa, os quais evidenciados nos dois semi-círculos externos da Figura 1.

Em seguida as entrevistas foram transcritas e arquivadas separadamente. Após a transcrição das entrevistas estas foram enviadas para o software Atlas Ti. Por meio desse programa foi realizada a categorização na qual as transcrições eram relidas visando caracterizar cada frase de acordo com os códigos das variáveis. Em cada parágrafo foram acrescentados também os códigos do entrevistado que o pronunciou.

Após a categorização das entrevistas, foram criados arquivos individuais para cada uma delas a partir de um relatório emitido pelo software citado. Estes arquivos foram ordenados internamente, agrupando os parágrafos que tratavam do mesmo tema. Em seguida foi realizada a codificação aberta, que consiste em redigir memorandos, ou seja, anotações analíticas provenientes da comparação e das ideias do pesquisador que emergiram ao longo desta pesquisa. 
Figura 1: Objetivos e Variáveis

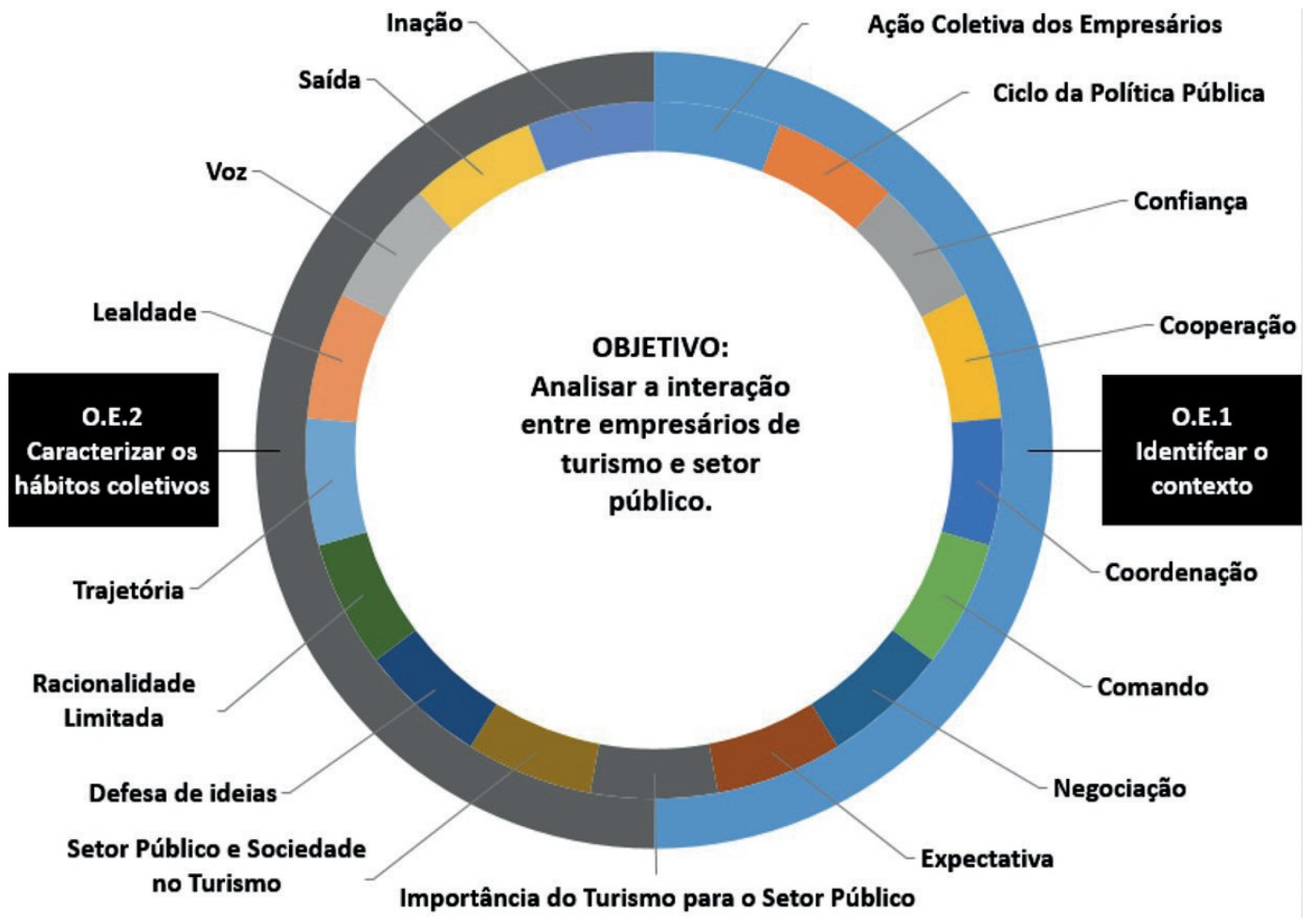

Fonte: Os autores (2018)

Então, foi realizada a codificação axial, ou seja, associar as categorias em duas grandes temáticas relacionadas aos objetivos específicos da pesquisa: identificar o contexto da interação e caracterizar os hábitos coletivos de pensamento e ação presentes nessa. Assim, estas etapas de análise dos dados, possibilitaram a construção de conhecimentos sobre a interação entre empresários e empresários e setor público ligados ao turismo em Morretes, PR, Brasil, expostos na seção de resultados.

\section{Resultados}

O município de Morretes está localizado no estado do Paraná, no sul do Brasil, conforme demonstrado na Figura 2. Morretes, fundado como povoado em 1721 e elevado a cidade em 1869, possui um histórico econômico de destaque nos ciclos do ouro e da erva-mate e em 2018, contava com uma população de cerca de 16.360 pessoas (https://cidades.ibge.gov.br/brasil/pr/morretes, recuperado em 16 de dezembro, 2018).

O turismo no município é caracterizado pela presença de visitantes em busca de atividades em áreas naturais, da gastronomia local, além do patrimônio cultural local. O deslocamento a Morretes partindo de Curitiba, capital do estado do Paraná, situada a aproximadamente setenta quilômetros, já é um atrativo turístico. Além da autopista convencional, é comum os visitantes se deslocarem até a cidade pela Estrada da Graciosa - que possui belas paisagens, ou pelo trem turístico que sai diariamente de Curitiba.

Por ser uma região de Mata Atlântica, o município conta com diversos recursos naturais, dentre os quais o Parque Nacional de Saint Hilare. Em termos gastronômicos, Morretes se destaca pelo barreado, ilustrado na parte superior esquerda da Figura 2. Como exposto por Gimenes (2011:161), o barreado é um prato típico do litoral paranaense, elaborado a partir de "carne bovina cozida exaustivamente com condimentos, em uma panela de barro hermeticamente fechada com goma de farinha de mandioca e servido com farinha de mandioca e banana". Dada a relevância desse prato o Sebrae (Serviço Brasileiro de Apoio às Micro e Pequenas Empresas), em conjunto com a Adetur Litoral (Agência de Desenvolvimento 
do Turismo Sustentável do Litoral do Paraná) e empresários solicitaram o registro do Barreado enquanto Indicação Geográfica do Litoral do Paraná.

\section{Figura 2: Morretes, Paraná, Brasil}

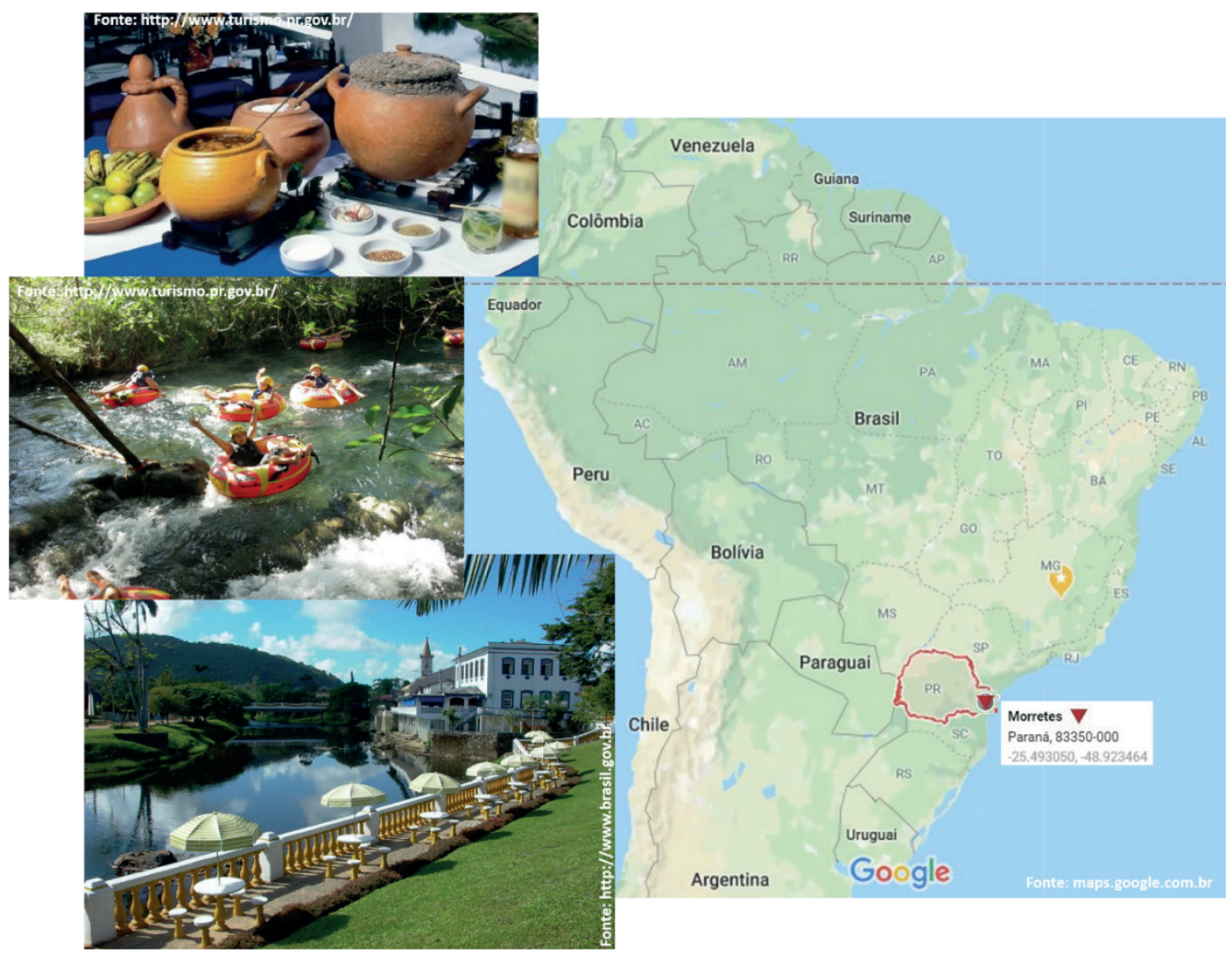

Fonte: (http://www.turismo.pr.gov.br, recuperado em 18 de dezembro, 2017; http://www.brasil.gov.br, recuperado em 18 de dezembro, 2017; http://maps.google.com.br, recuperado em 18 de dezembro, 2017)

De acordo com o IPARDES (2008) o turismo tem uma importante contribuição na geração de emprego e renda no litoral paranaense, sendo ele formado predominantemente por empreendimentos de pequeno porte. A ocupação da mão de obra local no turismo ocorre principalmente em empresas de alimentação e alojamento (https://extrator.ipea.gov.br, recuperado em 20 de agosto de 2017). A região do litoral paranaense, da qual o município faz parte, apresenta um crescimento do número de empresas de turismo a partir dos anos 2000 (Ipardes, 2008; Kushano et al., 2013)

A partir das análises, conforme descrito nos procedimentos metodológicos, constatou-se que a cidade recebe predominantemente visitantes, provenientes de Curitiba e que portanto não pernoitam. Também foi identificada uma fragilidade do órgão público de turismo local, com poucos funcionários e recursos, os quais ainda eram divididos com outras áreas como Esporte e Cultura. E ainda, o turismo local tem considerável dependência de alguns poucos empreendimentos ligados à gastronomia e uma influência na demanda causada pelo trem que transporta visitantes de Curitiba. A concentração, como expõe o entrevistado E2, "acaba beneficiando só os restaurantes, esquecendo dos outros que vivem do turismo na cidade, por exemplo quem vende o artesanato, o sorvete, morretes sofre com essa falta de permanência do turista".

Os principais agentes relacionados ao turismo em Morretes identificados na pesquisa são descritos no gráfico a seguir, o qual deve ser interpretado no sentido horário. 


\section{Gráfico 1: Agentes da interação empresários-setor público em Morretes}

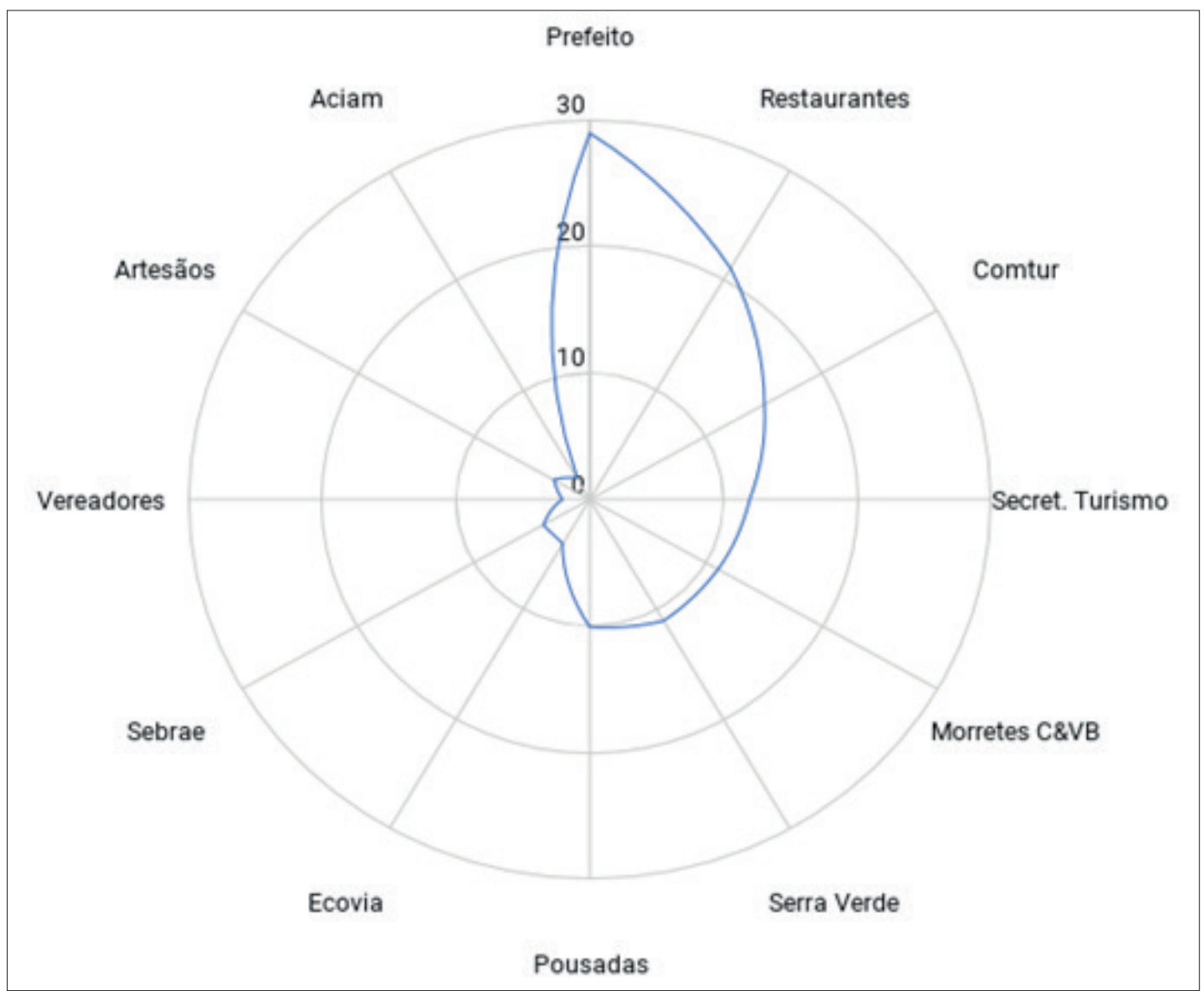

Fonte: Os autores (2018)

O Gráfico 1 demonstra que o chefe do executivo é o agente mais citado entre os entrevistados. Ele, em conjunto com a órgão municipal de turismo e o conselho municipal, revelam a importância que os entrevistados atribuem ao poder executivo no turismo local. Entre os empresários os mais citados foram os restaurantes, seguidos do Morretes Convention \& Visitor Bureau, a agência de turismo Serra Verde Express (responsável pelo trem) e as pousadas locais. Dentre os citados, mas com menor frequência, estão a Concessionária Ecovia (que administra a autopista BR 277), o Sebrae, os vereadores, os artesãos e a Associação Comercial Industrial e Agropecuária de Morretes (Aciam). O gráfico foi elaborado com agentes citados duas ou mais vezes, portanto, entidades como Adetur e Abrasel (Associa o Brasileira de Bares e Restaurantes), dentre outras, foram citadas, porém uma única vez, por isso não constaram.

Para os empresários de Morretes o setor público não é apenas um agente de segurança, limpeza e normatizador, ele é percebido também como um agente de apoio diante de problemas ou crises. Entre empresários menores e o setor público, a persuasão está presente na interação, ou seja, os primeiros tentam convenver o segundo a realizar alguma ação, sem que eles tenham uma contrapartida. Esta persuasão se manifesta por parte dos empresários menores que buscam, perante o responsável pela pasta do turismo, apoio financeiro para ações de suas associações, como organização de eventos.

Já a interação dos empresários maiores com o setor público tem traços de barganha. Eles com frequência expressam suas necessidades predominantemente ao chefe do poder executivo, arguementando que a sua contribuição ocorre em termos de emprego e renda para o município. Entre os esforços de convencimento estão a influência na escolha do responsável pelo turismo no munícipio, a reforma e o ordenamento de espaços públicos, a sinalização e a informação turística. Todavia, estes empresários maiores, ainda 
que tenham disposição para dar uma contrapartida financeira para a ação que pleiteiam, enfrentam dificuldade para estabelecer um diálogo permanente junto ao chefe do executivo. A perenidade dessa interação é afetada pela alteração das prioridades de cada novo agente político para esse cargo assim como a racionalidade limitada dos mesmos a respeito do turismo.

As decisões do setor público relacionadas ao turismo em Morretes são caracterizadas, segundo os empresários, pela racionalidade limitada. Essa dificuldade de compreensão diz respeito à falta de conhecimento técnico de turismo por parte do prefeito e principalmente daqueles que estão à frente da área no município. Os empresários destacam a necessidade do prefeito minimizar essa racionalidade limitada dialogando com eles e visitando-os pessoalmente e as áreas turísticas de cidade. Esse hábito, de acordo com os empresários, poderá estimular no chefe do executivo a percepção do turismo como uma das possibilidades para o município. Eles também realçam a importância do secretário de turismo, ter conhecimento sobre a área e de elaborar projetos para captação de recursos, além de ter interesse e disposição para trabalhar pelo turismo.

Nesse cenário, a cooperação entre empresários e setor público, ou seja, uma interação em que um está disposto a ajudar o outro no que for preciso, sem com isso levar algo em troca, ocorre mais na forma de troca de ideias, na promoção em feiras de turismo e na organização de eventos, como, por exemplo, o Carnaval e a tradicional Feira Agrícola e Artesanal de Morretes (Festa Feira). A cooperação para a agenda, quando ocorre, é mais frequente na construção das propostas de governo durante o período eleitoral ou em momentos de crises, como o bloqueio das vias de acesso em função das chuvas e o consequente deslizamento de encostas.

Assim, a cooperação para a efetiva formulação e avaliação de política pública é esporádica, predominando, como exposto, a aproximação entre empresários e o setor público na fase de implementação. Todavia, uma interação na formulação em Morretes relevante foi a constituição do conselho de turismo e de um fundo. Mas houve um baixo êxito desses esforços devido ao pequeno apoio dado pelo chefe do executivo ao conselho e a oposição manifestada por parte de alguns empresários em relação à arrecadação da taxa de turismo a ser destinada ao fundo.

A reformulação da lei da taxa de turismo, foi um tema de interação entre empresários e o setor público. A taxa de turismo foi criada em Morretes pela Lei Municipal $\mathrm{n}^{\circ}$ 16/2005, mas foi alterada pela Lei Municipal n 186 / 2012 (Morretes, 2005; Morretes, 2012). Ela se destina ao desenvolvimento e fomento do turismo local, bem como para o desenvolvimento de políticas públicas de infraestrutura.

A taxa foi instituída como contraprestação à utilização, efetiva ou potencial, por parte de pessoas visitantes, da infraestrutura física implantada no município e do acesso e fruição ao patrimônio natural e histórico de Morretes. Contudo, ele foi marcada por um questionamento jurídico, visto que as atividades definidas no referido artigo, são atividades fins do Estado, prestadas universalmente a todos os cidadãos, sem distinção de fruição particular entre usuários, sejam eles visitantes ou moradores. Estas devem, portanto, serem financiadas por meio da receita proveniente dos impostos, não passíveis de contraprestação através de taxa.

À exceção da taxa de turismo, a inércia do setor público local em relação ao turismo raramente é rompida, pois, além dos aspectos citados, tem-se a limitação do orçamento da pasta. Este em grande parte é destinado à folha de pagamento e ainda é dividido com outros assuntos, como meio ambiente e cultura. Este cenário contribuiu para que os empresários colocassem em prática a ideia de criação do Morretes Convention \& Visitors Bureau como uma forma de ação coletiva e de impulsionar o turismo local.

Assim, parte do dever da atuação pública relacionada a divulgar a cidade é direcionada para esta organização privada e para outra empresa de turismo de maior porte que atua na cidade. Apesar desta contribuição com o turismo, os empresários recebem críticas por adotarem comportamentos menos preocupados com o desenvolvimento local, por exemplo, em relaçção à baixa priorização de fornecedores do município e os aspectos ambientais. Essa baixa preocupação com os efeitos do turismo está presente também na interação na medida em que os aspectos econômicos e políticos inerentes a esse fenômeno são preponderantes.

O conteúdo das entrevistas realizadas é sintetizado na figura a seguir, elaborada utilizando o software Vosviewer.

A Figura 3 sintetiza a interação entre empresários e setor público trazendo como principais ideias Morretes e restaurantes. Essas são rodeadas pelos aspectos barreado, Sebrae, Ilha (do Mel, Paraná), turista e Serra Verde. Também pode-se observar dois outros núcleos de ideias. Um que envolve Convention (\& Visitors Bureau), Conselho (municipal de turismo - Comtur), pousada e associação e outro formado por prefeito, secretaria (de turismo) e secretário. Cabe ressaltar que o software não reconheceu o acento das palavras secretário e associação. Assim, a síntese demosntra que é uma realidade a interação dos empresários com o setor público no turismo em Morretes. E que a articulação dos restaurantes e pousadas em torno da ideia do Convention está presente, mas estando presente o Comtur nesse contexto. Dessa forma, a seguir serão apresentadas as considerações finais da investigação. 
Figura 3: Síntese das Entrevistas

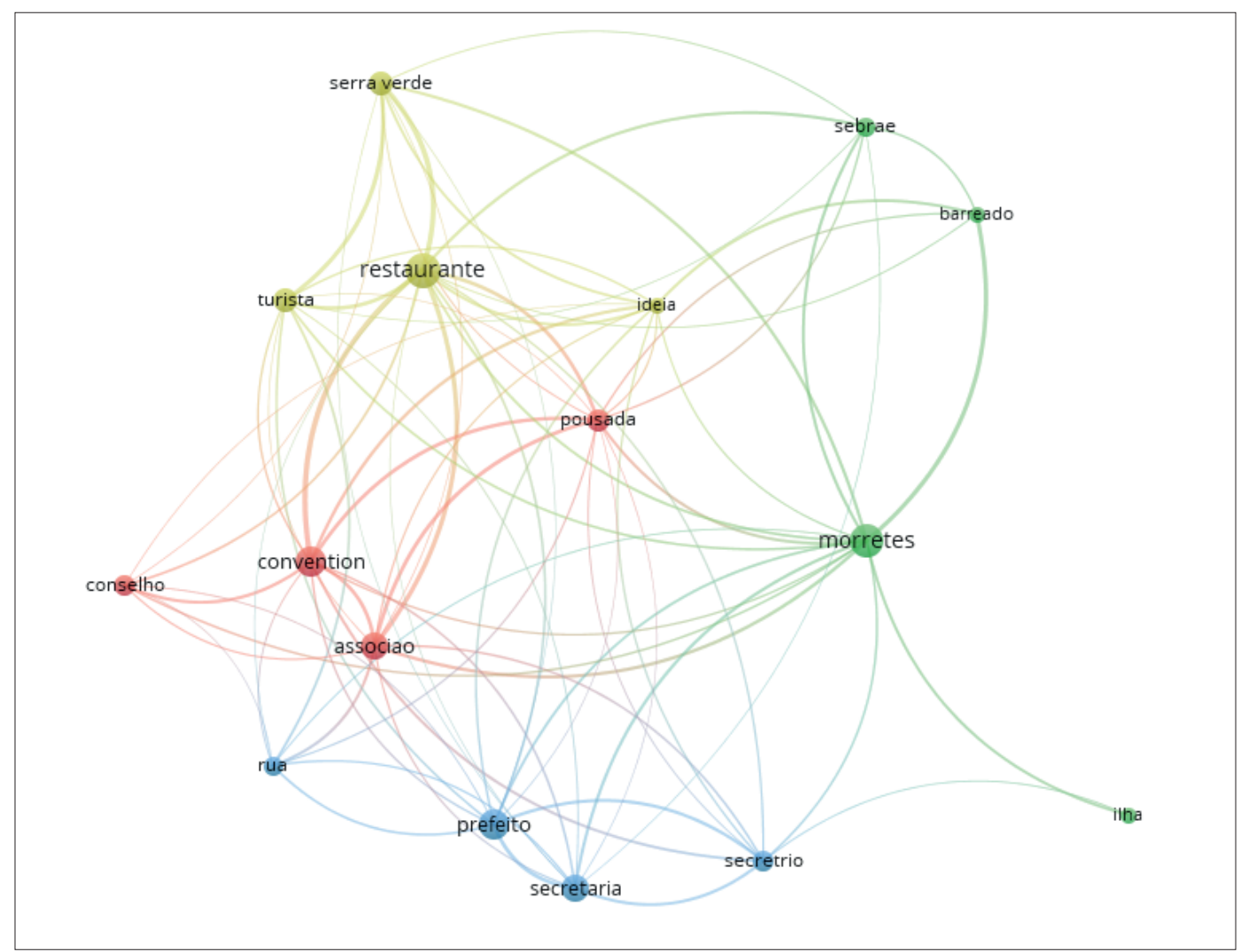

Fonte: Elaborado pelos autores

\section{Considerações Finais}

Os agentes mais atuantes nas políticas públicas de turismo são os empresários e o setor público. Portanto, a compreensão de seus hábitos coletivos ao interagirem para organizar o turismo é requisito para entender a formulação e a implementação das referidas políticas. A partir desse fundamento foi realizada uma investigação na cidade de Morreres, PR, Brasil, com o objetivo de identificar o contexto e os hábitos coletivos inerentes à interação empresários-setor público.

Em síntese, o contexto da interação em Morretes está relacionado a uma intensa relação com o turismo gastronômico, com alguns empresários proeminentes que destacam e influenciam inclusive as práticas comerciais de outros menores, bem como uma fragilidade do turismo no setor público.

A interação ocorre predominantemente na implementação e predomina a inércia do setor público local em relação ao turismo, em muito relacionada às limitações do órgão público de turismo e à racionalidade limitada dos agentes públicos em relação à área, especialmente do chefe do executivo. Esse ambiente de incerteza é intensificado com as eleições e a respectiva troca ds agentes públicos (chefe do executivo e comissionados que estão à frente da pasta do turismo). Assim, é notório que uma mudança de hábito em direção à contratação de servidores públicos turismólogos efetivos, com condições de trabalho adequadas, abre uma possibilidade concreta de colocar as políticas públicas de turismo locais em outro patamar.

Os empresários, por sua vez, apesar da experiência em seus negócios e da existência de diversas associações no município, manifestam dificuldades em se organizarem coletivamente para defenderem perante o setor público uma pauta coletiva e voltada para um turismo que promova o desenvolvimento local. Por isso é importante refletirem sobre o baixo tempo para dedicar ao coletivo, a competição 
(individualismo) e a busca por resultados imediatos. Também é importante que fortaleçam as associações empresariais enquanto organizações que reduzem as divergências entre os empresários e negociadoras dos mesmos perante o setor público.

Assim, a pesquisa possibilitou a compreensão sistematizada dos hábitos dos agentes locais, trazendo como implicação prática o alerta aos empresários e ao setor público de que a interação está em risco. As fragilidades dessa trazem uma tendência à saída, ou seja, uma desistência da interação manifestada pelo boicote dos principais empresários em relação às atividades do setor público e um desprezo desse em relação às emandas do setor privado.

Portanto, o fortalecimento de Morretes enquanto destino turístico passa pela reavaliação dos hábitos por parte dos empresários (principalmente os maiores) e do setor público. Para essa mudança de comportamento é importante considerarem o dever que possuem enquanto agentes dessa atividade capaz de gerar desenvolvimento econômico e social, que é o turismo.

Da mesma forma devem ter como balizador o fato de que estão lidando com uma política pública, logo a democracia é inerente à mesma. Por isso o conselho de turismo é tão relevante, por possibilitar uma interação marcada pelo diálogo para as políticas públicas de turismo locais . Mas a sua simples existência não é suficiente. O mesmo deve contemplar a diversidade de representações e a prevalência do interesse público, ou seja, ele equanto instituição democrática se distingue de uma associação empresarial. Além de reuniões frequentes, com tomada de decisão que gere efeitos nas políticas públicas, é importante que o Conselho tenha publicidade de seus atos e seja aberto para opiniões distintas, inclusive dos cidadãos não ligados diretamente ao turismo e dos turistas (por meio das mídias sociais).

A pesquisa apresentou como limitações a impossibilidade de enrevistar um maior número de agentes em função da restrição de tempo dos mesmos e dos pesquisadores, além do custo financeiro. Também não foi possível acompanhar a localidade por um período maior, observnado por exemplo as mudanças decorrentes da eleição para o chefe do executivo e para o legislativo municipal. Todavia, em termos teóricos a investigação destacou as contribuições da economia institucional para as investigações sobre políticas públicas de turismo. Ela também evidencia que as variáveis propostas se adequam à análise de destinos de menor porte, como Morretes, PR, Brasil. É certo que a pesquisa não esgota a discussão. Por isso pesquisas futuras devem ser replicadas em destinos de diferentes portes e regiões, observando os efeitos das eleições municipais, identificando instituições mais recorrentes na interação entre empresários e setor público e propondo outras não abordadas.

\section{Bibliografia}

Alchorne, S. C. A. 2012. Das políticas nacionais aos planos municipais: avanço da política pública de assistência social em metrópoles - estudo das cidades do Rio de Janeiro e de São Paulo. Tese (Doutorado em Serviço Social), Pontifícia Universidade Católica de São Paulo, São Paulo.

Anderson, J.E. 2011. Public Policymaking. Boston: Wadsworth.

Axelrod, R. 1986. La evolución de la cooperación: el dilema del prisionero y la teoria de juegos. Madrid: Alianza.

Béland, D. \& Zarzeczny, A. 2018. "Medical tourism and national health care systems: an institutionalist research agenda", Globalization and Health, 14(1):1-7.

Bryant, A. \& Charmaz, K. 2010. The Sage Handbook of Grounded Theory. London: Sage Publications.

Cabral, E. R., Dias, J. S. \& Gomes, S. C. 2015. "Gestão Ambiental em Espaços de Lazer e Turismo: as praias urbanas da Amazônia Brasileira". Rosa dos Ventos - Turismo e Hospitalidade, 7(2): 269-287.

Charmaz, K. 2009. A construção da teoria fundamentada: guia prático para análise qualitativa. Porto Alegre: Artmed.

Cintra, R. F., Amâncio-Vieira, S. F. \& Costa, B. K. 2016. "Stakeholder theory e institucionalismo sociológico: complementações para análise do Turismo local”. Revista Iberoamericana de Turismo, 6(1): 165-186.

Considine, M. 2005. Making Public Policy. Cambridge: Polity Press.

Diniz, E. 1994. "Empresariado, Regime Autoritário e Modernização Capitalista: 1964-1985". En: Soares, G.A.D.; D`Araújo, M.C (Eds.). 21 Anos de Regime Militar: balanços e perspectivas. Rio de Janeiro: Editora da Fundação Getúlio Vargas.

Dredge, D. \& Jenkins, J. 2007. Tourism Planning and Policy. Queensland: John Wiley and Sons.

Endres, A. V. \& Matias, E. M. 2018. "A trajetória das políticas de turismo a partir das perspectivas do institucionalismo histórico: o caso da Paraíba". Revista Iberoamericana de Turismo, 8(1): 221-235.

Feger, J.E., Abrahão, C.M.S, Gândara, J.M.G. \& Aguilar, C.R.V. 2019. "A regionalização do turismo no litoraldoParaná (Brasil): análise da rede de interação entre os stakeholders". Revista Acadêmica Observatório de Inovação do Turismo, 13(3):1-25. 
Falaster, C., Zanin, L. M. \& Guerrazzi, L. 2017. "Teoria institucional na pesquisa em turismo: Novas oportunidades de uma teoria em evolução", Revista Brasileira de Pesquisa em Turismo, 11(2): 270-293.

Gimenes, M. H. S. G. 2011. "Barreado: sabor, história e cultura no litoral paranaense”, História: Questões \& Debates, 54: 159-192.

Gomes, B.M.A.2018. Políticas Públicas de Turismo e os Empresários. São Paulo: All Print.

Gomes, B. M. A. \& Pessali, H. F. 2018. "Salida, Voz y Lealtad en las Políticas Públicas de Turismo: interacción entre empresarios y sector público". Estudios y Perspectivas en Turismo, 27(2): 336-354.

Gomes, B.M.A., Vargas-Sánchez, A. \& Pessali, H.F. 2014. "Interação Empresários-Setor Público no Turismo: uma análise institucional e neocorporativista na cidade de Huelva (Espanha)", Revista Brasileira de Pesquisa em Turismo, 8(3): 382-402.

Hirschman, A. 1973. Saída, Voz e Lealdade. São Paulo: Perspectiva.

Hodgson, G.M. 2017. "Prefácio" en Salles, A.O.T., Pessali, H.F. \& Fernández, R.G. Economia Institucional: fundamentos teóricos e históricos. São Paulo: Editora Unesp.

Ipardes (Instituto Paranaense de Desenvolvimento Econômico e Social). 2008. Cadeia produtiva do turismo no Paraná: estudo da região turística do Litoral. Curitiba: IPARDES.

Kushano, E.S., Filippim, M.L. \& Gândara, J.M.G. 2013. "Turismo no Litoral do Paraná: A perspectiva do Guia Brasil Quatro Rodas". Revista Rosa dos Ventos, 5(1): 60-76.

Mendonça, M.C.A. 2012. "Gestão de Potenciais Clusters Turísticos: uma proposta de metodologia de diagnóstico”. En: Beni, M. C. (Ed.). Turismo: planejamento estratégico e capacidade de gestão. Barueri: Manole.

Meydani, A. 2015. "Tour guides policy: Law or political culture? the case of pilgrims in the Holy Land", International Journal of Public Law and Policy, 5(3): 207-218.

Morretes. 2005. Lei n.16, de 31 de agosto de 2005. Altera a lei ${ }^{\circ} 21 / 98$ que cria o Comtur - Conselho Municipal de Turismo, institui o Fumtur - Fundo Municipal de Turismo e dá outras providências. Morretes, PR.

Morretes. 2012. Lei n.16, de 13 de agosto de 2012. Instituição e regulamentação da cobrança da Taxa de Turismo/Comtur morretes pelo Conselho Municipal De Turismo - Comtur Morretes - Paraná, criado pela lei municipal n $n^{\circ}$ 16/2005 de 31 de agosto de 2005 e dá outras providências. Morretes, PR.

Neale, W. 1987. "Institutions". Journal of Economic Issues, 21(3): 1177-1207.

Ostrom, E. 2014. "Do institutions for collective action evolve?" Journal of Bioeconomics, 16(1): 83-90.

Pessali, H. F. 2015. Nanoelementos da mesoeconomia: uma economia que não está no manuais. Curitiba: Editora UFPR.

Rodrigues, L. A. \& Castro, F. L. 2012. "Política cultural e gestão participativa". Políticas Culturais em Revista, 5(1): 142-155.

Sessa, A. 1976. "The Tourism Policy". Annals of Tourism Research, 3(5): 234-247.

Sinclair, M.T \& Stabler, M.2002. The Economics of Tourism. London: Taylor \& Francis.

Soto, J.L.P \& Gozález, M.V. 2005. "El impacto de la acción parlamentaria en una política gubernamental: el caso de la política turística española”. Gestión y Análisis de Políticas Públicas, 32(1): 33-58.

Strauss, A.1978. Negotiations: varieties, contexts process, social order. San Francisco: Jossey-Bass.

Strauss, A. \& Corbin, J. 2008. Pesquisa Qualitativa: técnicas e procedimentos para o desenvolvimento de teoria fundamenta. Porto Alegre: Artmed.

Swanson, J.R. \& Brothers. G.L. 2012. "Tourism policy agenda setting, interest groups and legislative capture". International Journal of Tourism Policy, 4(3): 206-221.

Velarde, F.G. 2017. "Estado y modelo de desarrollo turístico en la costa Norte del Perú: el caso de Máncora, Piura", PASOS. Revista de Turismo y Patrimonio Cultural, 15(4): 867-881.

Velasco, M. 2016. "Entre el poder y la racionalidad: gobierno del turismo, política turística, planificación turística y gestión pública del turismo". PASOS. Revista de Turismo y Patrimonio Cultural, 14(3): 577-594.

Yew, C.P. 2015. "Hong Kong's institutional incongruities and its tourism policy", Asian Education and Development Studies, 4(3): 312-329.

Recibido: 